\title{
A discount ordering strategy in two-level supply chain: A case study of textile industry
}

\author{
Mohammd Mokhtari $^{\mathbf{a}^{*}}$, Hassan Javanshir ${ }^{\mathrm{b}}$, Mehdi Kamali Dolatabadi ${ }^{\mathrm{a}}$, Faraz Maadanchi ${ }^{\mathrm{c}}$ and Laleh \\ Tashakori $^{\mathrm{d}}$
}

${ }^{a}$ Department of Textile, Engineering Faculty,Science and Research Branch, Islamic Azad University, Tehran, Iran.

${ }^{b}$ Department of Industrial Engineering, South Tehran Branch, Islamic Azad University, Tehran, Iran

${ }^{c}$ Department of Textile Industry, Amirkabir University, Tehran, Iran

${ }^{d}$ Institute of Toba Higher Educational Studies, Tehran, Iran

ARTI C L E I N F O AB S T R C T

Article history:

Received March 10, 2012

Received in Revised form

April, 15, 2012

Accepted 20 May 2012

Available online

May 292012

Keywords:

Supply chain management

Supplier selection

Texture industry

EOQ

Discount model
Supplier selection, inventory management and optimal lot sizing has been one of the most important issues in many industries especially in production planning issues associated with texture industry. The proposed model of this paper first introduces an algorithm to choose the best supplier and it determines the optimal lot size using discount strategy. The proposed model of this paper considers different influencing factors such as location, quality of materials, cost, and mutual trust for supplier selection, determines their relative importance weights and then a discounting method is used to determine the ordering lot-size. The preliminary results indicate that the proposed model of this paper can be implemented in texture industry, very efficiently since the ordering discount policy is not sensitive to changes on inventory holding and setup expenditures.

\section{Introduction}

Cost reduction has been one of the primary concerns among managers of many industries and the cost reduction in logistic is an essential importance where a significant amount of total cost of production is involved in this part (Aissaoui et al., 2007). There are many evidences to believe that selection of a good supplier can substantially reduce the cost of logistic and purchasing items (Xia \& Wu, 2007). However, selecting an appropriate supplier often involves various criteria, which makes the process complicated (Liu \& Hai, 2005). There are literally two source selection problems. In the first one, single resource or single supplier problem (SSP); all suppliers are capable of providing products and services with the same quality, delivery, customer satisfaction. In such circumstances, selection of supplier depends on cost of goods and services.

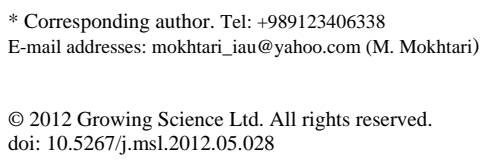


In the case of multi-resource, there are some limitations associated with supplier capacity, quality, and delivery and often no supplier can provide all demands. In such circumstances, order must be accomplished from various suppliers and two important decisions need to be made, which are supplier selection and order adjustment. Note that it is not always easy to conclude that a supplier with low service price necessarily cannot provide high quality services and vice versa. Multi criteria decision making (MCDM) is one of the most popular techniques for ranking different suppliers based on various criteria. The proposed model of this paper uses the idea of Knapsack problem (KP) for supplier assignment (Allahyari Soeini, et al., 2011). KP is a well known method in the literature where a person can fill his/her knapsack with different goods, differently and there are literally enormous number of solutions. Fig. 1 shows a typical KS problem. In this paper, we use this technique for a real-world applications from industry.

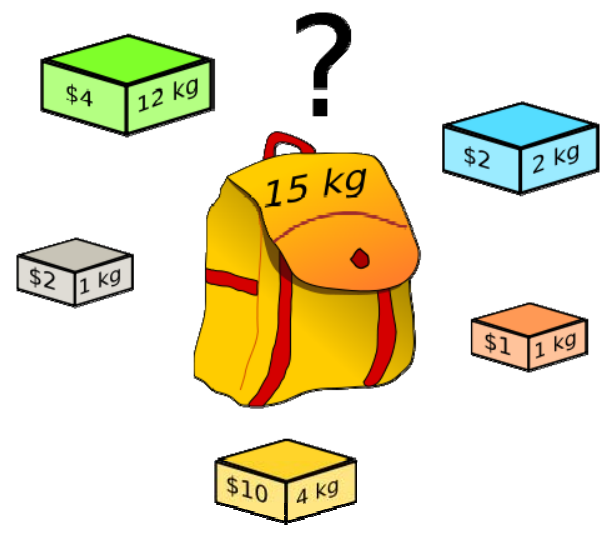

\section{Literature review}

Fig. 1. A typical KP problem

Selection of an appropriate supplier is normally involved with various criteria but two major criteria play important role for making an appropriate decision. Dickson et al. (1996) selected 23 criteria such as quality, on time delivery, guarantee, customer support, warranty, capacity for supplier selection by performing a survey among managers from different North American suppliers. Moore and Fearon (1973) are believed to be the first who proposed a computer based program for inventory management. Ghodsypour O’Brien (1998) proposed a remarkable work based on a decision support system for supplier selection using an integrated analytic hierarchy process (AHP) and linear programming.

Another MCDM technique for supplier selection is based on the adaptation of data envelopment analysis (DEA), which has been widely used among practitioners. Weber et al. (1991) performed a comprehensive review on supplier selection problems and categorized all problems into 74 different groups of problems in terms of price, delivery time, quality, capacity, etc. De Boer et al. (2001) suggested four stages for supplier selection: problem formulation, modeling criteria, problem specifications and final selection and they concluded that most people concentrate only on the last one as a necessary action for supplier selection.

Degraeve et al. (2004) performed an investigation on different models and compared the relative efficiency of them. Pujawan (2004) provided a conceptual model for supplier selection based on different criteria including production flexibility, delivery, product development, etc. Aissaoui et al. (2007) proposed some new methods for categorizing supplier selection strategies based on single or multi products. Kim et al. (2002) recommended a model for multi-stage supplier selection, where the proposed model was formulated as a nonlinear mathematical programming and demand was subject to uncertainty. Liao and Rittscher (2007) proposed a multi-objective supplier selection model under stochastic demand conditions where different constraints including cost, quality, delivery time and flexibility were considered, simultaneously. 
Xia and Wu (2007) studied supplier selection with multiple criteria in volume discount environments. Wadhwa and Ravindran (2007) studied vendor selection in outsourcing issues by considering discount as part of strategy. The proposed study of this paper is planning to propose a method for supplier selection on one of Iranian texture industries. We look for appropriate criteria for supplier selection for providing raw materials, including Tops, Color, disperse, Softener, retarder and acetic acid. Table 1 shows details of raw material consumption for 100 meters of string.

Table 1

A list of important raw materials

\begin{tabular}{lllll}
\hline & & Quantity $(\mathrm{Kg})$ & Price (Rials) & Description \\
\hline 1 & Tops & 103 & 40,000 & \\
2 & Color & 0.2 & 50,000 & This is the average figure \\
3 & Disperse & 0.1 & 30,000 & \\
4 & Softener & 0.2 & 25,000 & \\
5 & Retarder & 0.2 & 30,000 & This material is used proportion to color consumption \\
6 & Acetic acid & 0.3 & 10,000 & \\
\hline
\end{tabular}

The proposed model of this paper uses a method adapted from Allahyari Soeini et al. (2011), which is a multi-stage multi-product for supplier selection. Since a significant percentage of production cost is devoted to one of raw materials, Tops, discount policy is considered for this raw material. We first assume that there is no discount policy and then we setup appropriate discount limits and order size is determined by minimizing the total cost.

\section{The results}

The first step we need to important internal and external factors associated with supplier selection. These factors along with their relative importance are summarized in Table 2 as follows,

\section{Table 2}

Essential factors in supplier selection

\begin{tabular}{lccccc}
\hline Factor & Geographical location & Quality of materials & Delivery date & Cost & Mutual trust \\
\hline Relative importance & 2 & 6 & 4 & 7 & 6 \\
\hline
\end{tabular}

As we can observe from the results of Table 2, the cost of raw material, quality of materials as well as the existence of mutual trust play important role on supplier selection. Although delivery data has been considered as somewhat important factor but geographical location is not important according to what decision makers reported in this survey.

Traditionally, many organizations tried to use multi suppliers to reduce any risk but presently, many have decided to reduce the number of suppliers trying to work with limited remaining reliable suppliers. For the case study of this paper, we select one supplier as primary source and keep the information of a secondary supplier for the case of emergency issues. When there is not much changes on demand during the time horizon, we may use economic order quantity (EOQ), which can be calculated as follows,

$\mathrm{EOQ}=\sqrt{\frac{2 \mathrm{DS}}{\mathrm{H}}}$

where D, S and H represent demand, setup or ordering cost and inventory holding costs, respectively. For the case study demand is equal to 2575 per month or 30900 per year, the ordering and inventory costs are 500000 and 4000 per unit, respectively. The implementation of Eq. (1) yields 2780 for order size. Total ordering cost is calculated as follows, 
The implementation of Eq. (2) results TC $=1,247,117,554$. The ordering must be performed every 33 days and each time we must order 2780 units. In our case, Tops is over 99 percents of the raw material and Table 3 shows discounting policy.

Table 3

Discount policy

\begin{tabular}{ccc}
\hline Range & Discount & Offering price \\
\hline$<2000$ & 0 & 40,000 \\
$2000-3000$ & 10 & 36,000 \\
$>3000$ & 20 & 32,000 \\
\hline
\end{tabular}

To calculate the order quantity based on discount policy we first calculate EOQ for each range as follows,

Table 4

The order size for each range

\begin{tabular}{ccccc}
\hline Range & & & EOQ & Total cost \\
\hline$<2000$ & $2 * 30900 * 500,000$ & 4,000 & 2780 & Not valid \\
\hline $2000-3000$ & $2 * 30900 * 500,000$ & 3,600 & 2930 & $1,122,947,038$ \\
\hline$>3000$ & $2 * 30900 * 500,000$ & 3,200 & 3108 & $998,743,843$ \\
\hline
\end{tabular}

As we can observe from the results of Table 4, the optimal ordering strategy is 3108, which means we have to place the orders every 37 days. It is important to understand the effects of decrease/increase in both holding and setup costs and the results are summarized in Table 5.

Table

Sensitivity analysis

\begin{tabular}{|c|c|c|c|c|c|}
\hline Cost & Change & Effects & Range & $\begin{array}{l}\text { Initial } \\
\text { cost }\end{array}$ & $\begin{array}{l}\text { Permissible } \\
\text { change }\end{array}$ \\
\hline \multirow{6}{*}{$\begin{array}{l}\text { Order } \\
\text { cost }\end{array}$} & \multirow{3}{*}{ Increase } & NA & $<2000$ & 500,000 & - \\
\hline & & EOQ is valid up to 70 units of increase & $2000-3000$ & 500,000 & 524,272 \\
\hline & & EOQ is valid under any changes & $>3000$ & 500,000 & - \\
\hline & \multirow{3}{*}{ Decrease } & $\begin{array}{l}\text { EOQ must be reduced by } 780 \text { until it becomes } \\
\text { valid }\end{array}$ & $<2000$ & 500,000 & 258,890 \\
\hline & & EOQ remains valid for up to 930 reductions. & $2000-3000$ & 500,000 & 233,010 \\
\hline & & EOQ remains valid for up to 108 reductions. & $>3000$ & 500,000 & 466,019 \\
\hline \multirow{6}{*}{$\begin{array}{l}\text { holding } \\
\text { cost }\end{array}$} & \multirow{3}{*}{ Increase } & $\begin{array}{l}\text { EOQ must be reduced by } 780 \text { until it becomes } \\
\text { valid }\end{array}$ & $<2000$ & 4,000 & 7,725 \\
\hline & & EOQ remains valid for up to 930 reductions. & $2000-3000$ & 3,600 & 7,725 \\
\hline & & EOQ remains valid for up to 108 reductions. & $>3000$ & 3,200 & 3,433 \\
\hline & \multirow{3}{*}{ Decrease } & EOQ is not valid & $<2000$ & 4,000 & - \\
\hline & & EOQ is valid up to an increase of 70 units. & $2000-3000$ & 3,600 & 3,433 \\
\hline & & EOQ is valid under any changes. & $>3000$ & 3,200 & \\
\hline
\end{tabular}

As we can observe from the results of Table 5, the proposed ordering strategy is not much sensitive against changes on different parameters. Therefore, we can make sure that the proposed model of this paper provides reliable order size, which is not volatile against change in parameters. The proposed model of this paper can be implemented for other items involved in production but the cost reduction will not be as much as we had for the case of Tops since it is accounted for $99 \%$ of total raw materials in terms of the cost. 


\section{Conclusion}

In this paper, we have presented an empirical method to choose appropriate supplier in texture industry. The proposed model uses discount strategy for ordering Tops, which is a significant amount of raw material used in this industry. We have discussed the changes on inventory holding and setup costs and realized that the final ordering size will not be much sensitive. This is another successful implementation of traditional EOQ where it saves total cost, significantly. Note that profit margin in texture industry is normally low and there is a tight competition among producers for producing goods under reasonable offering price. In this paper, we have explained that the cost of inventory and ordering can be significant amount of cost of final product and a good strategy can help us increase efficiency of this sector.

\section{Acknowledgment}

The authors would like to thank the people who provided their insights on important criteria on supplier selection. We are also thankful to anonymous referees for constructive comments on earlier version of this work.

\section{References}

Aissaoui, N., Haouari, M., \& Hassini, E. (2007). Supplier selection and order lot sizing modeling: A review. Computers \& Operations Research, 34(12), 3516-3540.

Allahyari Soeini, R., Tashakori, L., Tashakori, J. \& Mokhtari, M. (2011), Design model to select suppliers for multi level - multi product industries. Communications in Computer and Information Science, 194(20). 604-615.

De Boer, L., Labro, E., \& Morlacchi, P. (2001). A review of methods supporting supplier selection. European Journal of Purchasing and Supply Management, 7(2), 75-89

Degraeve, Z., Labro, E., \& Roodhoofi, F. (2004). Total cost of ownership purchasing of a service: The case of airline selection at Alcatel Bell. European Journal of Operational Research, 156(1), 23-40.

Dickson, G. W. (1966). An analysis of vendor selection system and decisions. Journal of Purchasing, 2(1), 28-41.

Ghodsypour, S. H., \& O’Brien, C. (1998). A decision support system for supplier selection using an integrated analytic hierarchy process and linear programming. International Journal of Production Economics, 199-212.

Kim, B., Leung, J. M. Y., Taepark, K., Zhang, G., \& Lee, S. (2002). Configuring a manufacturing firm's supply network with multiple suppliers. IIE Transactions, 34(8), 663-677.

Liao, Z., \& Rittscher, J. (2007). A multi-objective supplier selection model under stochastic demand conditions. International Journal of Production Economics, 105(1), 150-159.

Liu, F. H. F., \& Hai, H. L. (2005). The voting analytic hierarchy process method for selecting supplier. International Journal of Production Economics, 97(3), 308-317.

Moore, D. L., \& Fearon, H. E. (1973). Computer-assisted decision-making in purchasing. Journal of Purchasing, 9(1), 5-25.

Pujawan, N. (2004). Assessing supply chain flexibility: a conceptual framework and case study. International Journal of Integrated Supply Management, 1(1), 79-97.

Wadhwa, V., \& Ravindran, R. (2007).Vendor selection in outsourcing. Computers and Operations Research, 34(12), 3725-3737.

Weber, C. A., Current, J. R., \& Desai, A. (2000). An optimization approach to determining the number of vendors to employ. Supply Chain Management: An International Journal, 5(2), 90-98.

Weber, C. A., Current, J. R., \& Benton, W. C. (1991).Vendor selection criteria and methods. European Journal of Operational Research, 50(1), 2-18. 
Xia, W., \& Wu, Z. (2007).Supplier selection with multiple criteria in volume discount environments. Omega, 35(5), 494-504.

Xia, W., \& Wu, Z. (2007). Supplier selection with multiple criteria in volume discount environments. Omega, 35(5), 494-504. 